\title{
185 rRNA is a reliable normalisation gene for real time PCR based on influenza virus infected cells
}

\author{
Suresh V Kuchipudi ${ }^{1 *}$, Meenu Tellabati ${ }^{1}$, Rahul K Nelli ${ }^{1}$, Gavin A White ${ }^{2}$, Belinda Baquero Perez ${ }^{1}$, Sujith Sebastian ${ }^{1}$, \\ Marek J Slomka ${ }^{3}$, Sharon M Brookes ${ }^{3}$, Ian H Brown³, Stephen P Dunham ${ }^{1}$ and Kin-Chow Chang ${ }^{1}$
}

\begin{abstract}
Background: One requisite of quantitative reverse transcription PCR (qRT-PCR) is to normalise the data with an internal reference gene that is invariant regardless of treatment, such as virus infection. Several studies have found variability in the expression of commonly used housekeeping genes, such as beta-actin (ACTB) and glyceraldehyde-3-phosphate dehydrogenase (GAPDH), under different experimental settings. However, ACTB and GAPDH remain widely used in the studies of host gene response to virus infections, including influenza viruses. To date no detailed study has been described that compares the suitability of commonly used housekeeping genes in influenza virus infections. The present study evaluated several commonly used housekeeping genes [ACTB, GAPDH, $18 \mathrm{~S}$ ribosomal RNA (18S rRNA), ATP synthase, $\mathrm{H}+$ transporting, mitochondrial F1 complex, beta polypeptide (ATP5B) and ATP synthase, $\mathrm{H}+$ transporting, mitochondrial Fo complex, subunit C1 (subunit 9) (ATP5G1)] to identify the most stably expressed gene in human, pig, chicken and duck cells infected with a range of influenza A virus subtypes.

Results: The relative expression stability of commonly used housekeeping genes were determined in primary human bronchial epithelial cells (HBECs), pig tracheal epithelial cells (PTECs), and chicken and duck primary lung-derived cells infected with five influenza A virus subtypes. Analysis of qRT-PCR data from virus and mock infected cells using NormFinder and BestKeeper software programmes found that 185 rRNA was the most stable gene in HBECs, PTECs and avian lung cells.

Conclusions: Based on the presented data from cell culture models (HBECs, PTECs, chicken and duck lung cells) infected with a range of influenza viruses, we found that $18 S$ rRNA is the most stable reference gene for normalising qRT-PCR data. Expression levels of the other housekeeping genes evaluated in this study (including ACTB and GPADH) were highly affected by influenza virus infection and hence are not reliable as reference genes for RNA normalisation.
\end{abstract}

Keywords: Reference gene, Housekeeping gene, qRT-PCR, Data normalisation, Influenza A viruses, H5N1, H1N1, $\mathrm{H} 2 \mathrm{~N} 3$

\section{Background}

Real-time PCR or quantitative reverse transcription PCR (qRT-PCR) is widely used to quantify changes in messenger RNA (mRNA) levels. In many cases, it is the only reliable and sensitive method of quantification of mRNA levels of low copy number targets [1]. There are several advantages of qRT-PCR over other conventional methods for measuring mRNA levels such as accurate

\footnotetext{
* Correspondence: suresh.kuchipudi@nottingham.ac.uk

${ }^{1}$ School of Veterinary Medicine and Science, University of Nottingham, Sutton Bonington Campus, College Road Loughborough, Leicestershire LE12 5RD, UK

Full list of author information is available at the end of the article
}

quantification, high sensitivity, large dynamic range, and potential for high throughput analysis [1]. However, the following factors need to be properly addressed to avoid erroneous qRT-PCR results: variability of RNA quantification and dispensing, and different efficiencies of reverse transcription (RT) and PCR [2]. Consequently, it is important to choose a reliable normalisation method to take into account errors introduced by these factors.

A widely used method for normalisation involves measuring the expression of an internal reference or "housekeeping" gene, which takes into account the potential error of RNA/cDNA loading, and variation of reverse transcription efficiency [3]. An ideal reference/

\section{Biomed Central}


housekeeping gene should be stably expressed across samples from different tissues, developmental stages, and experimental conditions. However, there is no single gene that can satisfy all these criteria. Nevertheless, it is important to ensure that the expression of a reference gene used in a particular experiment is not adversely affected by the treatment. Normalisation of gene expression based on a varying reference gene is likely to produce misleading results [4]. Three commonly used reference genes for normalising qRT-PCR data are $A C T B, G A P D H$, and $18 S$ rRNA [5]. However, several studies have reported that levels of $A C T B$ and GAPDH are highly variable among cell types, during cell differentiation and in cancers [6-10].

Virus infection of cells leads to a general inhibition of cellular macromolecular synthesis that is referred to as shut-off [11] and causes changes in global gene expression. Therefore, it is essential to validate reference genes to ensure their suitability for a specific experiment involving a particular virus and cell type [12]. Expression of many genes including $A C T B$ are significantly altered in human cell lines following infection with cytomegalovirus, human herpes virus-6, camelpox virus, severe acute respiratory syndrome (SARS) coronavirus and yellow fever virus [13]. Many studies determined the reliability of housekeeping genes in different cells infected with a range of different viruses [13-16], however to date no detailed study has been carried out to demonstrate suitability of reference genes that could be used in influenza A virus infected avian and mammalian cells.

Despite their reported instability and unsuitability as reference genes, ACTB [17-19] and GAPDH $[20,21]$ remain widely used for normalising qRT-PCR data in influenza infection studies. We examined the stability of $A C T B, G A P D H, 18 S$ rRNA, ATP5B and ATP5G1 to identify a suitable housekeeping gene for qRT-PCR normalisation of data from primary human bronchial epithelial cells, pig tracheal epithelial cells, chicken and duck lung cells infected with a range of low and high pathogenicity influenza A viruses.

\section{Results and discussion}

RNA expression stability of commonly used reference genes was studied in primary cells from human, pig, chicken and duck at $24 \mathrm{~h}$ following infection with five influenza A virus subtypes. Expression of $18 S$ rRNA, $A C T B$, GAPDH, ATP5B, ATP5G1 were compared using BestKeeper and NormFinder software programmes in virus and mock infected samples.

Raw crossing point $(\mathrm{Cp})$ values from each of the virus and mock infected samples $(n=6)$ were used to calculate standard deviation $[\mathrm{SD}( \pm \mathrm{Cp})]$ for all the reference genes using BestKeeper software (Table 1). Separate analyses were carried out for each cell type. Based on the
Table 1 Bestkeeper analysis of housekeeping genes showing variation in gene expression

\begin{tabular}{|c|c|c|c|c|}
\hline \multirow[b]{2}{*}{ HBECS } & \multicolumn{4}{|c|}{ Standard deviation $[ \pm \mathrm{Cp}]$} \\
\hline & $18 S$ rRNA & ACTB & GAPDH & ATP5B/ ATP5G1* \\
\hline H5N1 tyTR05 & 0.474 & 2.484 & 1.196 & 1.620 \\
\hline Swine H1N1 & 0.375 & 0.484 & 0.465 & 0.413 \\
\hline USSR huH1N1 & 0.462 & 1.046 & 0.740 & 0.662 \\
\hline Average & 0.437 & 1.338 & 0.800 & 0.899 \\
\hline \multicolumn{5}{|l|}{ PTECs } \\
\hline Swine H1N1 & 0.265 & 0.354 & 0.344 & 0.413 \\
\hline H5N1 tyEng91 & 0.090 & 0.330 & 0.310 & 0.140 \\
\hline H5N1 tyTR05 & 0.100 & 0.420 & 0.240 & 0.450 \\
\hline Average & 0.152 & 0.368 & 0.298 & 0.334 \\
\hline \multicolumn{5}{|c|}{ Chicken lung cells } \\
\hline H5N1 tyEng91 & 0.160 & 0.510 & 0.480 & - \\
\hline H5N1 tyTR05 & 0.140 & 0.230 & 0.260 & - \\
\hline Avian H2N3 & 0.200 & 0.230 & 0.200 & - \\
\hline Average & 0.167 & 0.323 & 0.313 & - \\
\hline \multicolumn{5}{|l|}{ Duck lung cells } \\
\hline H5N1 tyEng91 & 0.380 & 0.480 & 0.690 & - \\
\hline H5N1 tyTR05 & 0.160 & 0.660 & 1.290 & - \\
\hline Avian $\mathrm{H} 2 \mathrm{~N} 3$ & 0.110 & 0.190 & 0.430 & - \\
\hline Average & 0.217 & 0.443 & 0.803 & - \\
\hline
\end{tabular}

Bestkeeper analysis $(\mathrm{n}=6)$ of standard deviation $( \pm \mathrm{Cp}$ ) showed 185 rRNA is the most stable gene in all the four cell types at $24 \mathrm{~h}$ post-infection with the influenza virus subtypes used in this study. ${ }^{*}$ ATP5B and ATP5G1 were included in HBECs and PTECs analysis respectively.

variation (SD) in expression, $18 S$ rRNA was the most stable among all the genes tested in HBECs, PTECs, and chicken and duck lung cells $24 \mathrm{~h}$ following infection with various influenza virus subtypes (Table 1). Expression stability of remaining reference genes varied between virus treatments and species. Further pair-wise correlation and regression analysis was carried out using BestKeeper software to calculate the correlation between the expression of each of the candidate reference genes and the BestKeeper index. $\mathrm{Cp}$ values for all three viruses and mock infected samples $(n=12)$ were used for this analysis and separate analyses were carried out for each cell type. In all four cell types, a strong significant correlation $(0.843<\mathrm{r}>0.962)$ was detected between $18 S \mathrm{rRNA}$ gene expression and the BestKeeper index $(\mathrm{p}<0.01)$ (Table 2) compared with the other genes. GAPDH was the next best gene based on the correlation coefficient values in HBECs, PTECs and duck lung cells $(0.792<\mathrm{r}>0.871)$. For chicken lung cells $A C T B$ was the second best reference gene $(\mathrm{r}=0.845)$.

NormFinder software calculates a stability number from the intra- and inter-group variations which represent a measure of the systematic error introduced by each of the reference genes when used to normalise the 
Table 2 Bestkeeper correlation and regression analysis of housekeeping genes

\begin{tabular}{llccc}
\hline & 18S rRNA & GAPDH & ACTB & ATP5B/ ATP5G1cp \\
\cline { 2 - 5 } & vs. & vs. & vs. & vs. \\
\cline { 2 - 5 } & BestKeeper & BestKeeper & BestKeeper & BestKeeper \\
\cline { 2 - 5 } & \multicolumn{4}{c}{ Coefficient of correlation [r] } \\
\hline HBECs & 0.962 & 0.871 & 0.709 & 0.543 \\
\hline PTECs & 0.843 & 0.743 & 0.741 & - \\
\hline Chicken lung cells & 0.944 & 0.832 & 0.845 & - \\
\hline Duck lung cells & 0.836 & 0.792 & 0.542 & \\
\hline
\end{tabular}

Pairwise correlation and regression analysis using Bestkeeper correlation analysis $(n=12)$ found 185 rRNA as the most suitable housekeeping gene. Note that highest correlation between $18 \mathrm{~S}$ rRNA and the BestKeeper index $(\mathrm{p}<0.01)$ was found in all the four cell types used. ${ }^{*}$ ATP5B and ATP5G1were included in HBECs and PTECs analysis respectively.

data. NormFinder analysis of reference genes in HBECs (Figure 1a), PTECs (Figure 1b), chicken (Figure 1c) and duck (Figure 1d) lung cells also indicated that $18 S$ rRNA was the best among the housekeeping genes comparison, with lowest stability numbers ranging from 0.003 to 0.016. Based on the NormFinder stability numbers, GAPDH was the second best gene, while $A C T B$ was the most unstable gene in all the four cell types.
BestKeeper software is robust against sampling errors but it requires that none of the genes analyzed are coregulated. In contrast NormFinder is less affected by coregulation of genes but could be sensitive to sampling errors [22]. Hence, the use of both software programmes in the present study provided a robust and accurate analysis of the expression stability of the candidate housekeeping genes.
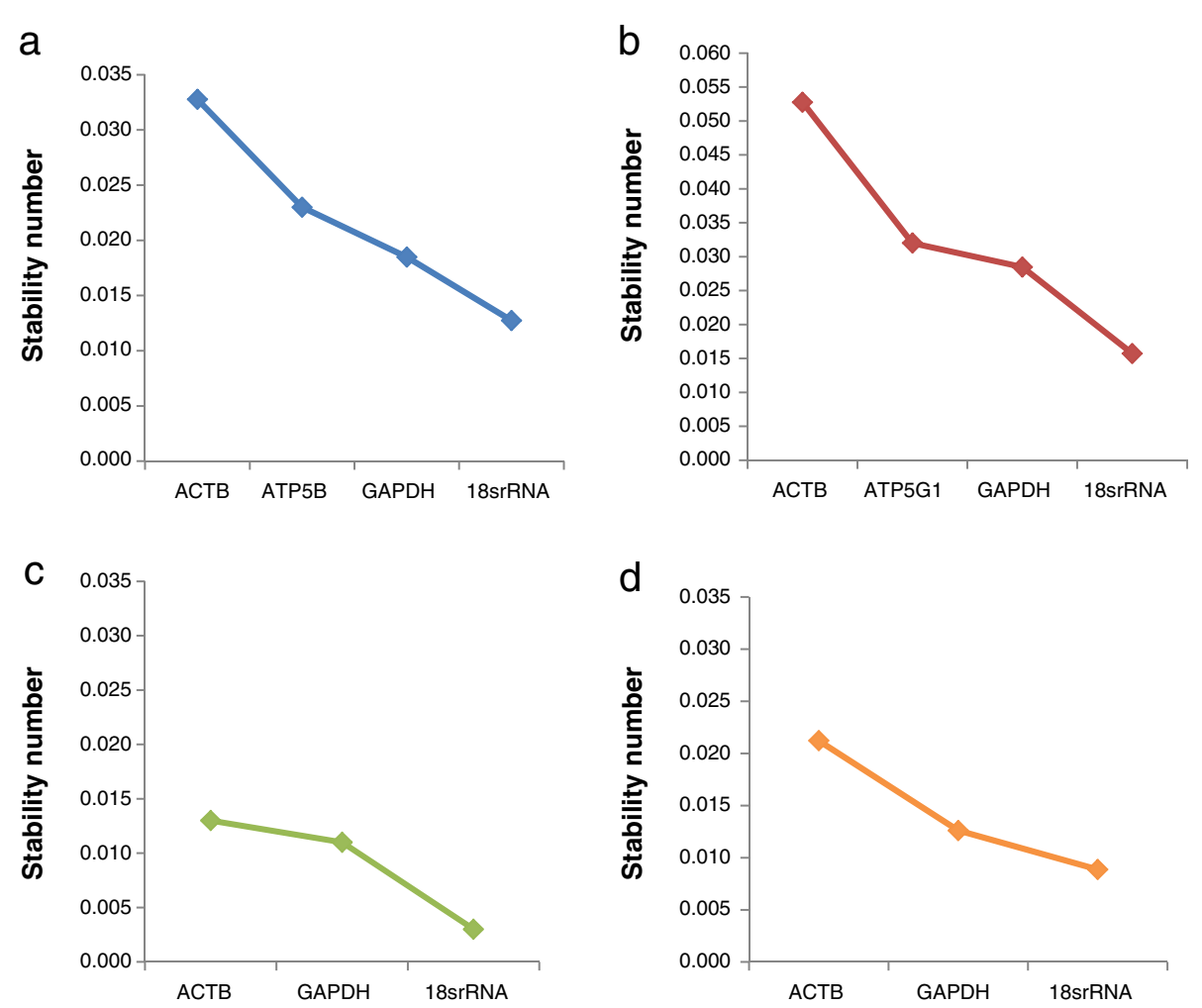

Figure 1 NormFinder analysis of housekeeping genes in human (a), pig (b), chicken (c) and duck (d) cells showing stability numbers, which are a measure of the systematic error introduced by each of the reference genes when used to normalise the qRT-PCR data. In all of the four cell types, $18 \mathrm{~S}$ rRNA was the best reference gene as evidenced by the lowest stability numbers (0.003 to 0.016$)$ among all of the genes compared. GAPDH was the second gene of choice for all the four host species. ACTB was the most unstable gene in all four host cell types. Data represent stability numbers which were calculated by combining intra- and inter- group variations $(\mathrm{n}=12)$. 
In summary we concluded that $18 S$ rRNA is a suitable housekeeping gene, while $A C T B$ and GAPDH are not as reliable for normalising $\mathrm{qRT}$-PCR data from influenza virus infected HBECs, PTECs, chicken and duck cells.

Ribosomal RNA, the central component of the ribosome is an abundant and one of the most conserved genes in all cells [23]. We found that expression of $18 \mathrm{~S}$ rRNA was least affected by the infection of influenza $\mathrm{A}$ virus subtypes in all the cell types used in this study. Several studies have also recommended ribosomal RNA as the best choice as a reference gene compared with other genes in a variety of cell culture systems [24-27].

A technical limitation of using $18 S$ rRNA as a normaliser is that random primers must be used for cDNA synthesis rather than oligo-(dT) since rRNA does not contain a poly-A tail. Use of oligo-(dT) has been suggested as being preferable over random oligomers for cDNA synthesis in order to avoid multiple initiations and to obtain a single initiation event per individual mRNA [28]. To overcome this problem a co-application reverse transcription (Co-RT) with $18 S$ rRNA sequencespecific primer combined with oligo-( $\mathrm{dT}$ ) reaction could be used to increase the sensitivity and improve accuracy of reverse transcription [29]. Another criticism of using $18 S$ rRNA for normalising mRNA expression is that the ribosomal fraction may not truly represent the overall cellular mRNA population [29]. However, influenza virus infection inhibits cellular macromolecular synthesis (shut-off) and causes global gene expression changes [30-35] affecting mRNA levels of many genes. In our laboratory, we performed transcriptome analyses of influenza virus infected human, pig, chicken and duck cells using DNA-microarrays, and found that many genes including $A C T B, G A P D H$, SDH1, EEF1G, PPI, TBP and $A T P 5 B$ to be differentially regulated (data not shown). Despite the perceived disadvantages, owing to its consistency and stability of expression in influenza virus infected cells, $18 S$ rRNA is the most appropriate gene to be used as a reference gene.

Tracheo-bronchial epithelial cells from human, pig and lung fibroblasts from chicken and ducks were used in the present study. It is likely that the expression stability of $18 S$ rRNA could be different among other cells and host species. However, previous studies found that the $18 S$ rRNA gene was the most stable gene in resting and polyclonal $\mathrm{T}$ cell activated human peripheral blood mononuclear cells (PBMCs), [10], and hepatic cells in chicken [36,37] and geese [38].

A recent study comparing the expression of 11 housekeeping genes including $A C T B$ and GAPDH found that $A C T B$ and ribosomal protein L4 (RPL4) were the most stable in H5N1virus infected chicken embryo fibroblasts (CEF) cells and GAPDH as the most stable gene in normal CEF cells [39]. However, this study did not include
$18 S$ rRNA for comparison, it used only one H5N1 virus isolate and the data were analysed using the GeNorm software programme [39]. In the present study the data were subjected to robust analyses with two different software programmes that are based on different algorithms. Furthermore, NormFinder software used in this study provides results consistent with GeNorm using higher sample sizes [40].

Other strategies such as normalising against total RNA [1] [for example ribogreen (molecular probes), LabChip (Agilent)] and genomic DNA [41] have also been used. A major drawback of normalising against total RNA is that it doesn't account for the inherent variation in the reverse transcription or PCR reactions [42]. There is also a major problem for normalising against genomic DNA, because the extraction rates of RNA and DNA may vary between different samples, with yields of DNA often being low. The presence of variable haplotypes in certain tumour cells [1] and multiple copies of particular loci in replicating bacteria compared to non replicating bacteria [43] are some of the additional problems of normalising against genomic DNA. Use of multiple reference genes rather than one has also been suggested as a robust method for providing accurate normalisation [44]. However, it may not always be feasible to use multiple reference genes due to limitations of the sample availability, cost and even when using multiple reference genes, accuracy remains dependent on the variability of the chosen reference genes [1]. Although these methods are not mutually exclusive, normalising qRT-PCR data using a single internal reference gene continues to be the most widely used method.To conclude, in this study for influenza A infected host cells the most suitable housekeeping gene appears to be $18 S$ rRNA.

\section{Methods}

\section{Viruses and cell cultures}

A H2N3 low pathogenicity avian influenza virus (LPAIV) (A/mallard duck/England/7277/06), a classical swine H1N1 (A/sw/Iowa/15/30), a human H1N1 (A/USSR/77), a classical H5N1 highly pathogenic avian influenza virus (HPAIV) (A/turkey/England/50-92/91, hereafter referred to as H5N1 tyEng91) and a contemporary H5N1 Eurasian lineage (clade 2.2.1) HPAIV (A/turkey/Turkey/1/ 05, hereafter referred to as H5N1 tyTR05) were used in this study. All the viruses were grown in 10-day-old embryonated chicken eggs by allantoic inoculation. Viruses were titrated using Madin-Darby canine kidney (MDCK) cells by a previously described immunocytochemical focus assay [45].

Primary human bronchial epithelial cells (HBECs) (CC2540) from Lonza UK were used. Pig tracheal epithelial cells (PTECs) were isolated from stripped tracheobronchial mucosae from 3- to 4-month-old euthanized 
pigs as previously described [46]. Briefly, washed minced mucosae were incubated at $4^{\circ} \mathrm{C}$ overnight with $0.06 \mathrm{U} / \mathrm{ml}$ pronase (Sigma) in 1:1 DMEM:F-12 medium. Supernatant containing cells were centrifuged and washed in DMEMGlutamax. Both HBEC and PTECs were cultured in bronchial epithelial growth medium (BEGM, CC-3170, Lonza UK). Primary lung cell cultures were extracted from lungs of euthanized 4-week-old broiler chickens and 6-week-old Pekin ducks and were grown in Dulbecco's modified Eagle's medium (DMEM, Invitrogen Ltd., Paisley, UK) with antibiotics using a method that we previously described [45].

\section{Virus infection of cells}

All cells were grown in 6 well cell culture plates (Corning) and three wells were used for each cell and virus type. HBECs and PTECs were cultured in serum-free BEGM, chicken and duck lung cells in DMEM : Ham's F12 (1:1), containing 2\% Ultroser G (Pall Biosepra), $50 \mathrm{ng} / \mathrm{ml}$ TPCK trypsin (Sigma) and $100 \mathrm{U} / \mathrm{ml}$ penicillin$100 \mu \mathrm{g} / \mathrm{ml}$ streptomycin. All cells were pre-incubated with the virus for $2 \mathrm{~h}$ to achieve a multiplicity of infection (MOI) of 1.0. Mock infected controls in three wells were performed by adding equivalent amount of PBS instead of virus in medium. The following virus-cell combinations were used for the infection study.

\section{HBECS}

H5N1 tyTR05, USSR huH1N1 and swine H1N1.

PTECs

H5N1tyEng91, H5N1 tyTR05 and swine H1N1.

\section{Chicken and duck cells}

H5N1 tyEng91, H5N1 tyTR05 and avian H2N3.

After $2 \mathrm{~h}$, cells were rinsed three times with PBS and incubated in fresh medium until harvest at $24 \mathrm{~h}$ postinfection (PI). Virus infection of cells was confirmed by immuno-chemical staining using a murine monoclonal antibody to influenza nucleoprotein (Abcam) with a DAKO Envision system as previously described [45] (Data not shown).

\section{Extraction of total RNA}

Total RNA from cells was extracted using RNeasy plus QIAshredder Kit (Qiagen) following the manufacturer's instructions. The concentration of extracted RNA in samples was determined using UV absorption with a NanoDrop1000 spectrophotometer (Thermo Scientific) and the quality of RNA was assessed using Agilent RNA 6000 nano kit (Agilent) following the manufacturer's instructions.

\section{CDNA synthesis}

A two step qRT-PCR assay was used in which a first strand cDNA was synthesized with $10 \mu \mathrm{g}$ of the total RNA sample using random primers and Superscript III First-strand synthesis system (Invitrogen) following the manufacturer's instructions.

\section{Primers}

Expression of ACTB, GAPDH and $18 S$ rRNA were analyzed in virus and mock infected cells from all of the four species. In addition $A T P 5 B$ and ATP5G1 were also included for human and pig analysis. Commercially available primers obtained from Primer Design Ltd (UK) were used for human and pig genes and hence the sequences are not available. Primers for chicken genes were designed using Primer express software version 2.0 (Applied Biosystems) and the same primers were used for both chicken and duck samples. Sequence details for the chicken primers: $A C T B$ - TGCTGCGCTCGTTGTTGA (Fwd), TCGTCCCCGGCGAAA (Rev), GAPDH -GAAGCTTACTGGAATGGCTTTCC (Fwd), CGGCAGGTCAGGTCAACAA (Rev), and $18 S$ rRNA- TGTGCCGCTAGAGGTGAAATT (Fwd), TGGCAAATGCTTTCGCTTT (Rev). Chicken primers were provided by Sigma (UK).

\section{Quantitative PCR}

Quantitative RT-PCR for the relative expression analysis of selected genes was carried out using the LightCycler ${ }^{\circledR}$ 480 SYBR green master mix (Roche) and all the reactions were carried out using the LightCycler ${ }^{\circledR} 480$ (Roche). A master mix was prepared for each target gene comprising $10 \mu$ l of SYBR Green master mix, $0.8 \mu$ l each of forward and reverse primers $(900 \mathrm{nM})$ and $3.6 \mu \mathrm{l}$ of nuclease free water. Five micro litres of cDNA diluted at 1:25 was used per reaction in a total reaction volume of $20 \mu$ l. PCR cycling parameters were as follows; denaturation at $95^{\circ} \mathrm{C}$ for $10 \mathrm{~min}$ followed by 45 cycles of $95^{\circ} \mathrm{C}$ for $15 \mathrm{~s}, 60^{\circ} \mathrm{C}$ for $30 \mathrm{~s}$, $72^{\circ} \mathrm{C}$ for $1 \mathrm{~s}$ followed by cooling at $40^{\circ} \mathrm{C}$ for $10 \mathrm{~s}$. Product specificity was evaluated by melting curves. Each total RNA sample was amplified in triplicate and the mean values were used for further analysis. Crossing point $(\mathrm{Cp})$ values were calculated in the absolute quantification mode using the second derivative method. Serial dilutions of a pooled cDNA sample for each cell type (combination of virus and mock infected samples) were used to plot a standard curve. Using the slope of the standard curve, PCR efficiencies were calculated using the formula, Efficiency $=-1+10^{(-1 / \text { slope })}$. Raw $\mathrm{Cp}$ values were used for BestKeeper analysis while expression values generated by the relative standard curve method were used for NormFinder analysis. PCR efficiencies of all the genes tested ranged between $90-100 \%$. 


\section{Determination of expression stability of reference genes} BestKeeper and NormFinder software programmes which utilise pair-wise comparison and model based approaches respectively were used to determine the stability of each of the housekeeping genes in the various virus and mock infected groups following the developer's instructions.

BestKeeper software [47] was used initially to calculate standard deviation (SD) $( \pm \mathrm{Cp}$ ) based on the raw $\mathrm{Cp}$ values from each of the virus infected and control samples $(n=6)$ for all of the reference genes. SD values provide a measure of the variation and are used to determine the expression stability of candidate reference genes. Further pair-wise correlation- regression analysis was also carried out with all the virus and mock infected $\mathrm{Cp}$ values for each cell type $(n=12)$. BestKeeper combines all the reference genes for a sample into BestKeeper index using the geometric mean of $\mathrm{Cp}$ values of each of the candidate gene. The software then undertakes pair-wise correlation analyses, to determine the relationship between each gene by assigning each gene combination a Pearson correlation coefficient ( $\mathrm{r}$ ) and a probability ( $\mathrm{p}$ ) value. The software combines highly correlated genes into an index and the software then compares the correlation between each gene pair and the BestKeeper index to calculate the correlation coefficient ( $\mathrm{r}$ ) value. In a panel of housekeeping genes, the ideal housekeeping gene is the one with the highest correlation coefficient ( $\mathrm{r}$ ).

NormFinder software [22] uses a model based evaluation strategy where the software first calculates intraand inter-group variation and combines the two into a stability value. The stability value is a combination of the two sources of variation and hence is a practical measure of the systematic error introduced by a gene when used as a housekeeping gene for data normalization. A gene with a low stability number is less likely to introduce systematic error that a gene with a high stability number. Raw non-normalized expression values generated by the standard curve method were used for NormFinder analysis $(\mathrm{n}=12)$.

\section{Competing interests}

The authors declare no competing interests.

\section{Authors' contributions}

SVK carried out the statistical analysis of the data, designing of the primers and drafted the manuscript. SVK, MT, GAW and RKN carried out the GRT-PCR assays. GAW, RKN performed human and pig cell infections, RNA extractions and CDNA synthesis. BB and SS performed chicken and duck primary cell cultures, virus infections, RNA extractions and CDNA synthesis. SPD, MJS and $\mathrm{SMB}$ conducted the H5N1 infection studies in high containment facilities (ACDP3/SAPO4). SPD, IHB participated in the study design and coordination. SVK and KCC conceived the study, participated in the design and helped to draft the manuscript. All authors read, provided input and approved the final manuscript.

\section{Acknowledgement}

We acknowledge the support of many staff at the AHVLA for their assistance during the course of this work. This work was part funded by the BBSRC the University of Nottingham and DEFRA (MJS, SMB and IHB).

\section{Author details}

${ }^{1}$ School of Veterinary Medicine and Science, University of Nottingham, Sutton Bonington Campus, College Road Loughborough, Leicestershire LE12 5RD, UK. ${ }^{2}$ School of Biosciences, University of Nottingham, Sutton Bonington Campus, College Road, Loughborough, Leicestershire LE12 5RD, UK. ${ }^{3}$ Virology department, Animal Health and Veterinary Laboratories Agency, Weybridge, Addlestone, UK.

Received: 12 April 2012 Accepted: 5 October 2012 Published: 8 October 2012

\section{References}

1. Huggett J, Dheda K, Bustin S, Zumla A: Real-time QPCR normalisation; strategies and considerations. Genes and Immunity 2005, 6:279-284.

2. Bustin SA: Quantification of mRNA using real-time reverse transcription (PCR QPCRx): trends and problems. J Mol Endocrinol 2002, 29:23-39.

3. McCurley A, Callard G: Characterization of housekeeping genes in zebrafish: male-female differences and effects of tissue type, developmental stage and chemical treatment. BMC Mol Biol 2008, 9:102

4. Bustin SA: Absolute quantification of mRNA using real-time reverse transcription polymerase chain reaction assays. J Mol Endocrinol 2000, 25:169-193.

5. Suzuki T, Higgins PJ, Crawford DR: Control selection for RNA quantitation. Biotechniques 2000, 29:332-337.

6. Tokunaga K, Nakamura Y, Sakata K, Fujimori K, Ohkubo M, Sawada K, Sakiyama S: Enhanced expression of a glyceraldehyde-3-phosphate dehydrogenase gene in human lung cancers. Cancer Res 1987, 47:5616-5619.

7. Schek N, Hall BL, Finn OJ: Increased glyceraldehyde-3-phosphate dehydrogenase gene expression in human pancreatic adenocarcinoma. Cancer Res 1988, 48:6354-6359.

8. Zhong H, Simons JW: Direct comparison of GAPDH, beta-actin, cyclophilin, and 28S rRNA as internal standards for quantifying RNA levels under hypoxia. Biochem Biophys Res Commun 1999, 259:523-526.

9. Yeung MM, Melgar S, Baranov V, Oberg A, Danielsson A, Hammarstrom S, Hammarstrom ML: Characterisation of mucosal lymphoid aggregates in ulcerative colitis: immune cell phenotype and TCR-gammadelta expression. Gut 2000, 47:215-227.

10. Bas A, Forsberg G, Hammarstrom S, Hammarstrom ML: Utility of the housekeeping genes $18 \mathrm{~S}$ rRNA, beta-actin and glyceraldehyde-3phosphate-dehydrogenase for normalization in real-time quantitative reverse transcriptase-polymerase chain reaction analysis of gene expression in human T lymphocytes. Scand J Immunol 2004, 59:566-573.

11. Beloso A, Martinez C, Valcarcel J, Santaren JF, Ortin J: Degradation of cellular mRNA during influenza virus infection: its possible role in protein synthesis shutoff. J Gen Virol 1992, 73(Pt 3):575-581.

12. Dheda K, Huggett JF, Chang JS, Kim LU, Bustin SA, Johnson MA, Rook GA, Zumla A: The implications of using an inappropriate reference gene for real-time reverse transcription PCR data normalization. Annal Biochem 2005, 344:141-143.

13. Radonic A, Thulke S, Bae HG, Muller MA, Siegert W, Nitsche A: Reference gene selection for quantitative real-time PCR analysis in virus infected cells: SARS corona virus, Yellow fever virus, Human Herpesvirus-6, Camelpox virus and Cytomegalovirus infections. Virol J 2005, 2:7.

14. Pena AA, Bols NC, Marshall SH: An evaluation of potential reference genes for stability of expression in two salmonid cell lines after infection with either Piscirickettsia salmonis or IPNV. BMC Res Notes 2010, 3:101.

15. Watson S, Mercier S, Bye C, Wilkinson J, Cunningham AL, Harman AN: Determination of suitable housekeeping genes for normalisation of quantitative real time PCR analysis of cells infected with human immunodeficiency virus and herpes viruses. Virol J 2007, 4:130

16. Xue $J$, Cheng XW: Using host $28 \mathrm{~S}$ ribosomal RNA as a housekeeping gene for quantitative real-time reverse transcription-PCR (qRT-PCR) in virus-infected animal cells. Curr Protoc Microbiol 2010, Chapter 1:Unit1D.2

17. Chakrabarti A, Vipat V, Mukherjee S, Singh R, Pawar S, Mishra A: Host gene expression profiling in influenza A virus-infected lung epithelial (A549) cells: a comparative analysis between highly pathogenic and modified H5N1 viruses. Virol J 2010, 7:219.

18. Hayashi T, Chaichoune K, Patchimasiri T, Hiromoto Y, Kawasaki Y, Wiriyarat W, Chakritbudsabong W, Prayoonwong N, Chaisilp N, Parchariyanon S, et al: Differential host gene responses in mice infected with two highly 
pathogenic avian influenza viruses of subtype H5N1 isolated from wild birds in Thailand. Virology 2011, 412:9-18.

19. Watanabe $C$, Uchida $Y$, Ito H, Ito T, Saito T: Host immune-related gene responses against highly pathogenic avian influenza virus infection in vitro differ among chicken cell lines established from different organs. Vet Immunol Immunopathol 2011, 144:187-199.

20. Barber MR, Aldridge JR Jr, Webster RG, Magor KE: Association of RIG-I with innate immunity of ducks to influenza. Proc Natl Acad Sci U S A 2010, 107:5913-5918.

21. Josset L, Textoris J, Loriod B, Ferraris O, Moules V, Lina B, N'guyen C, Diaz JJ, Rosa-Calatrava M: Gene expression signature-based screening identifies new broadly effective influenza a antivirals. PLoS One 2010, 5(10):e13169. doi:10.1371/journal.pone.0013169.

22. Andersen $\mathrm{CL}$, Jensen $J \mathrm{~L}$, Ørntoft TF: Normalization of Real-Time Quantitative Reverse Transcription-PCR Data: A Model-Based Variance Estimation Approach to Identify Genes Suited for Normalization, Applied to Bladder and Colon Cancer Data Sets. Cancer Res 2004, 64:5245-5250.

23. Smit S, Widmann J, Knight R: Evolutionary rates vary among rRNA structural elements. Nucleic Acids Res 2007, 35:3339-3354.

24. Selvey S, Thompson EW, Matthaei K, Lea RA, Irving MG, Griffiths LR: Beta actin - an unsuitable internal control for RT-PCR. Mol Cell Probes 2001, 15:307-311.

25. Goidin D, Mamessier A, Staquet MJ, Schmitt D, Berthier-Vergnes O: Ribosomal 18S RNA prevails over glyceraldehyde-3-phosphate dehydrogenase and beta-actin genes as internal standard for quantitative comparison of mRNA levels in invasive and noninvasive human melanoma cell subpopulations. Anal Biochem 2001, 295:17-21.

26. Aerts $J$, Gonzales MI, Topalian SL: Selection of appropriate control genes to assess expression of tumor antigens using real-time RT-PCR. Biotechniques 2004, 36:84-1.

27. Schmid H, Cohen CD, Henger A, Irrgang S, Schlondorff D, Kretzler M: Validation of endogenous controls for gene expression analysis in microdissected human renal biopsies. Kidney Int 2003, 64:356-360.

28. Kimmel AR, Berger SL: Preparation of CDNA and the generation of cDNA libraries: overview. Methods Enzymol 1987, 152:307-316.

29. Lj Z, Altmann SW: mRNA and 18S?ÇôRNA coapplication?Çôreverse transcription for quantitative gene expression analysis. Anal Biochem 2005, 345:102-109.

30. Geiss GK, Salvatore M, Tumpey TM, Carter VS, Wang X, Basler CF, Taubenberger JK, Bumgarner RE, Palese P, Katze MG, et al: Cellular transcriptional profiling in influenza A virus-infected lung epithelial cells: the role of the nonstructural NS1 protein in the evasion of the host innate defense and its potential contribution to pandemic influenza. Proc Natl Acad Sci U S A 2002, 99:10736-10741.

31. Tong HH, Long JP, Li D, DeMaria TF: Alteration of gene expression in human middle ear epithelial cells induced by influenza $A$ virus and its implication for the pathogenesis of otitis media. Microb Pathog 2004, 37:193-204

32. Baskin CR, Garcia-Sastre A, Tumpey TM, Bielefeldt-Ohmann H, Carter VS, Nistal-Villan E, Katze MG: Integration of clinical data, pathology, and CDNA microarrays in influenza virus-infected pigtailed macaques (Macaca nemestrina). J Virol 2004, 78:10420-10432.

33. Kawada J, Kimura H, Kamachi Y, Nishikawa K, Taniguchi M, Nagaoka K, Kurahashi H, Kojima S, Morishima T: Analysis of gene-expression profiles by oligonucleotide microarray in children with influenza. J Gen Virol 2006, 87:1677-1683.

34. Reemers SS, van Haarlem DA, Groot Koerkamp MJ, Vervelde L: Differential gene-expression and host-response profiles against avian influenza virus within the chicken lung due to anatomy and airflow. J Gen Virol 2009, 90:2134-2146.

35. Reemers SS, Groot Koerkamp MJ, Holstege FC, van Eden W, Vervelde L: Cellular host transcriptional responses to influenza $A$ virus in chicken tracheal organ cultures differ from responses in in vivo infected trachea. Vet Immunol Immunopathol 2009.

36. Wang PH, Ko YH, Chin HJ, Hsu C, Ding ST, Chen CY: The effect of feed restriction on expression of hepatic lipogenic genes in broiler chickens and the function of SREBP1. Comp Biochem Physiol B Biochem Mol Biol 2009, 153:327-331.

37. Dridi S, Buyse J, Decuypere E, Taouis M: Potential role of leptin in increase of fatty acid synthase gene expression in chicken liver. Domest Anim Endocrinol 2005, 29:646-660.
38. Ding ST, Yen CF, Wang PH, Lin HW, Hsu JC, Shen TF: The differential expression of hepatic genes between prelaying and laying geese. Poult Sci 2007, 86:1206-1212.

39. Yue H, Lei XW, Yang FL, Li MY, Tang C: Reference gene selection for normalization of PCR analysis in chicken embryo fibroblast infected with H5N1 AIV. Virol Sin 2010, 25:425-431.

40. Mehta R, Birerdinc A, Hossain N, Afendy A, Chandhoke V, Younossi Z, Baranova A: Validation of endogenous reference genes for qRT-PCR analysis of human visceral adipose samples. BMC Mol Biol 2010, 11:39.

41. Talaat AM, Howard ST, Hale W, Lyons R, Garner H, Johnston SA: Genomic DNA standards for gene expression profiling in Mycobacterium tuberculosis. Nucleic Acids Res 2002, 30:e104.

42. Stahlberg A, Kubista M, Pfaffl M: Comparison of reverse transcriptases in gene expression analysis. Clin Chem 2004, 50:1678-1680.

43. Rocha EP: The replication-related organization of bacterial genomes. Microbiology 2004, 150:1609-1627.

44. Vandesompele J, De Preter K, Pattyn F, Poppe B, Van Roy N, De Paepe A Speleman F: Accurate normalization of real-time quantitative QPCR data by geometric averaging of multiple internal controls. Genome Biol 2002, 3:34.

45. Kuchipudi SV, Dunham SP, Nelli R, White GA, Coward VJ, Slomka MJ, Brown $\mathrm{IH}$, Chang KC: Rapid death of duck cells infected with influenza: a potential mechanism for host resistance to H5N1. Immunol Cell Biol 2012, 90:116-123.

46. Nelli RK, Dunham SP, Kuchipudi SV, White GA, Baquero BP, Chang P, Ghaemmaghami A, Brookes S, Brown IH, Chang KC: Mammalian Innate Resistance to Highly Pathogenic Avian Influenza H5N1 Virus Infection is Mediated through Reduced Pro-inflammation and Infectious Virus Release. J Virol 2012, 86(17):9201-9210.

47. Pfaffl MW, Tichopad A, Prgomet C, Neuvians TP: Determination of stable housekeeping genes, differentially regulated target genes and sample integrity: BestKeeper - Excel-based tool using pair-wise correlations. Biotechnol Lett 2004, 26:509-515.

doi:10.1186/1743-422X-9-230

Cite this article as: Kuchipudi et al: 18S rRNA is a reliable normalisation gene for real time PCR based on influenza virus infected cells. Virology Journal 2012 9:230.

\section{Submit your next manuscript to BioMed Central and take full advantage of:}

- Convenient online submission

- Thorough peer review

- No space constraints or color figure charges

- Immediate publication on acceptance

- Inclusion in PubMed, CAS, Scopus and Google Scholar

- Research which is freely available for redistribution

Submit your manuscript at www.biomedcentral.com/submit
C Biomed Central 